\title{
A Computer-Based Emission Inventory
}

\author{
G. Schimak and W. Winiwarter \\ Dept. Telematics \& Telecommunication and Dept. Environmental Planning \\ Austrian Research Centers
}

Key words: emission inventory, air quality, regional planning

\begin{abstract}
To get quick and reliable information about the current load of pollutants caused by different kind of sources, like point (industry), line (traffic) or area (agriculture) emission inventories are an adequate tool. The below discussed system will show an emission inventory system installed for the federal province Upper Austria which integrates data from several different data sources.
\end{abstract}

\section{INTRODUCTION}

For a basic understanding of air pollution and its effects, but also for possible abatement measures, information on the emissions of pollutants is required. Attempts to compile such information as emission inventories have started in the 1960's, and have improved ever since. Emission inventories not only compile the total load of a certain substance released into the atmosphere, but also the contribution of a certain source sector, or a specific source itself. Even further, they provide the opportunity to add potential "new" sources, like new power plants, roads or industry or housing areas. Thus they can easily serve as instruments for public and regional planning, but also as foundations for studies on air quality.

Together with air quality models, emission inventories will help predict scenario concentrations of air pollutants. As stand-alone instruments, they help to set priorities in terms of identifying heavily loaded areas with potential health risks, as a guidance for setting up monitoring equipment, 
and as a decision tool whether a certain (proposed) emission source is acceptable for a specific site.

In order to be able to apply the wealth of information available, it is necessary to have access to the full amount of data acquired for setting up the inventory. At the same time, this access needs to be well organized and structured, such that simple questions as well as complex requests can be handled in a simple manner and time-efficient.

Current emission inventories, if they are database driven, usually store the results of the inventory calculations at a relatively high aggregated level (e.g.: CORINAIR [Jol, 1997] ). Evaluations down to the input data are mostly not possible, hampering the reproducibility as well as possibilities for scenario calculations.

\section{BASIC STRATEGIES FOR CREATING AN EMISSION INVENTORY}

There are two basic concepts for emission inventories, the bottom up and the top down concept. In the bottom-up approach, plants, roads and houses are assessed for a certain geographic area (grid square or administrative unit). Their emissions are estimated and summed up for this area. The inventory then consists of a grid of many such cells.

The top-down inventory uses statistical data to assess emissions for the whole area (usually administrative unit) and then breaks it down to smaller units using additional surrogate statistics (see e.g. Orthofer and Winiwarter, 1998 , for details).

Generally, a bottom up approach will be more tedious and costly to assemble when there are many single sources to be specifically dealt with. But, it will provide very detailed and specific information, which may be available down to the stack level sometimes. Both approaches agree in covering all sources of a specific substance.

All emission inventories in practice comprise a mixture of both approaches, the extent of which mostly depending on the scale of an inventory. This scale in turn very much relies on the problem which an inventory is created for.

Inventories dealing with greenhouse gas emissions tend to have very large scales (usually: the whole earth) and very low spatial resolutions 
(usually: countries), at the smallest units where potential measures are intended to be applied [IPCC, 1995].

At the opposite extreme, an urban emission inventory may require very local information for transport modeling in street canyons or pollution exposure assessment of city dwellers [Bøhler et al., 1999]. Here statistical data cannot adequately reflect the detail of information required, as the exact location of a stack as a starting point of a plume occasionally entering the street canyon.

For relatively high resolutions and small areas, the integration of existing data into the inventory seems extremely useful. Legal regulations in most countries in the world require emitters to forward information on their emissions to regulation authorities. While the validity of such data has been questioned [Henry et al., 1997], and valuable validation exercises as described by Sturm et al. [1999] have seldom been performed, this nevertheless is the official information an authority will have to apply. Knowing about the shortcomings helps them to use the data, but first of all it is necessary to be able to access them.

\section{THE UPPER AUSTRIAN EMISSION INVENTORY SYSTEM}

We describe here an emission inventory created for the use within an environmental authority (Abt. U-LE, Amt der OÖ-Landesregierung) in Upper Austria. Upper Austria is one of nine Austrian provinces, having an area of about $12000 \mathrm{~km} 2$ and 1.3 million inhabitants.

\subsection{Data preparation and data modeling}

For localization of input data we focused, corresponding to the requested results, on three main sources:

- Point Sources: All industrial sites with workforce $>50$ were considered point sources, as well as all installations obliged to report emissions to the authority.

- Line Sources: Traffic emissions were regarded line sources, as much as traffic counts were available, along the major roads.

- Area Sources: All other emissions (domestic heating, local traffic, small industry, etc.) were treated as area sources, with the whole province 
divided into 445 "Gemeinden" (municipalities, communities) and 1276

"Zählsprengel" (smallest administrative units in Austria).

Following the scheme given in Figure1, models were developed according to the technology involved in the emitting process. We used the SNAP (systematic nomenclature of air pollutants) classification of the European CORINAIR inventorying system [Jol, 1997] as a basis. For each of the 11 SNAP categories and for a number of subcategories, specific emission models were developed.

\begin{tabular}{cl}
\hline SNAP & Description \\
\hline 01 & COMBUSTION IN ENERGY AND TRANSFORMATION INDUSTRIES \\
02 & NON-INDUSTRIAL COMBUSTION PLANTS \\
03 & COMBUSTION IN MANUFACTURING INDUSTRY \\
04 & PRODUCTION PROCESSES \\
05 & EXTRACTION AND DISTRIBUTION OF FOSSIL FUELS AND \\
& GEOTHERMAL ENERGY \\
06 & SOLVENT AND OTHER PRODUCT USE \\
07 & ROAD TRANSPORT \\
08 & OTHER MOBILE SOURCES AND MACHINERY \\
09 & WASTE TREATMENT AND DISPOSAL \\
10 & AGRICULTURE \\
11 & OTHER SOURCES AND SINKS \\
\hline
\end{tabular}

Table 1: Definition of the SNAP '97 categories

The inventory covers the compounds $\mathrm{SO} 2, \mathrm{NOx}, \mathrm{NMVOC}, \mathrm{CO}, \mathrm{CO} 2$, and PM10 (particulate matter).

\subsection{Principal computing approach}

The overall approach for the model algorithm was based on the following governing principle.

As far as available, specific data from different on-line emission measurements, from occasional measurements or from energy and technological information derived from the questionnaires were used for the calculation of emissions. Missing data was replaced by default values, until the level of generic literature data (e.g. default emission factors) was reached (lowest priority).

By nature, the gets more detailed information for point sources reflecting the bottom up approach. The top-down approach is reflected in the calculation of area sources. 

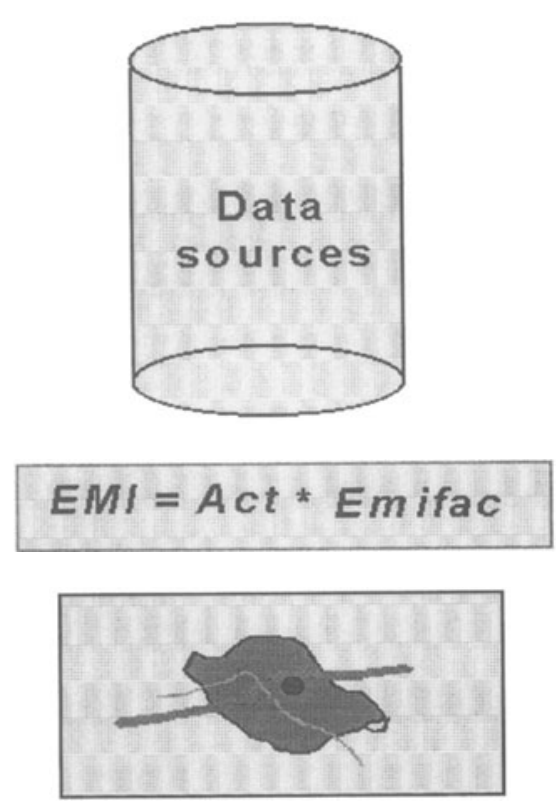

Figure 1: Abstract data model

\section{Input Data}

- Questionnaire

- Statistics

- Emission Factors

- Temporal Resolution

- Spatial Resolution

\section{Models}

emi $_{\mathrm{CO}}=$ activity $_{\mathrm{x}}{ }^{*}$ emifact $_{\mathrm{CO}}$

\section{Results}

Point / Line / Area Emission for $\mathrm{SO}_{2}$, Nox, NMVOC, $\mathrm{CO}, \mathrm{CO}_{2}$ and $\mathrm{PM}_{10}$

Emissions from point sources were specifically assessed using the questionnaires (the return of about $70 \%$ should be considered extremely high as participation was not compulsory for industry). Economic activities were classified according EUROSTAT's NACE-code. In most cases, emission fluxes were only available for specific installments of a site. All other emissions were estimated multiplying activity numbers (fuel use, solvent use, etc.) with emission factors. Emission factors were available according to the CORINAIR SNAP scheme, mostly from international sources [McInnes, 1996; U.S. EPA, 1997].

Traffic emissions, which comprise all line sources, were calculated from traffic counts and national emission factors [Keller and Hausberger, 1998], only in specific cases (like road dust and railway) international factors [U.S.EPA, 1997; McInnes, 1996] were used.

For area sources, emission factors were applied again. Industrial activity numbers derived from questionnaires sent to randomly selected sites for specific size classes of industry. Statistical information on heating installations was available for the smallest administrative units, again specific national emission factors were applied (Stanzel et al., 1995). Natural 
sources (forests, lightning and soils are included) were considered area sources.

\subsection{Data storage concept and the three-layer structure}

The nature of an emission inventory is for a relatively infrequent input of mass data. The majority of applications consists of specific requests to certain emissions stored in the database. Thus the very comprehensive calculation routines needed to model the emissions are not triggered at each query.

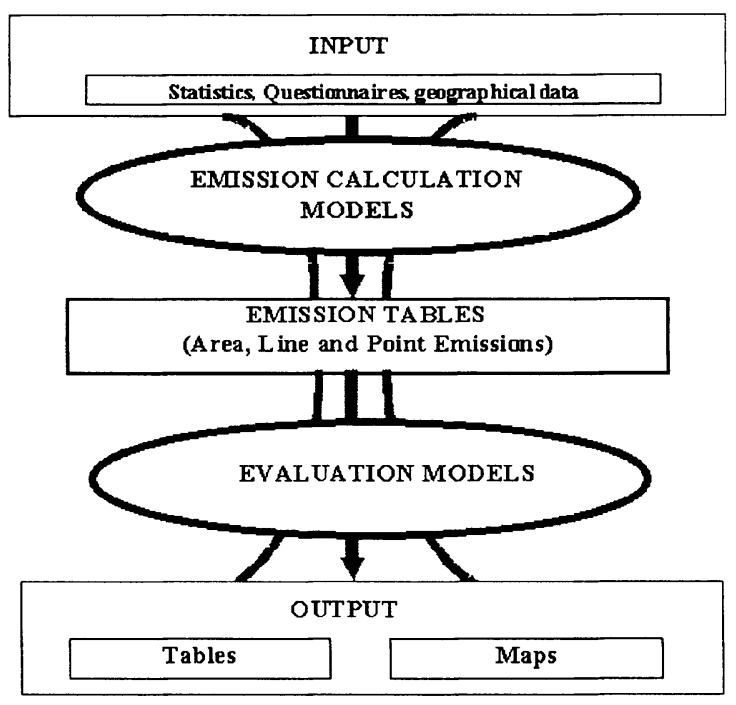

Figure 2: Three layer structure

Thus the basic concept behind the model computation is a three layer structure (Figure 2). The first layer defines and implements all tables which are used for data entry, statistical data and data used in the geographic information system. The different model computation algorithms use different parts of these basic tables. The algorithms perform multiple aggregation, disaggregation or multiplying procedures. The results are stored in the second layer, the so called emission tables, separately for point, line and area emissions. All evaluations are based on these three tables. The emission evaluation is the third layer. Within this layer different kinds of listings (reports) as well as geographical evaluations are located. 


\section{TECHNICAL IMPLEMENTATION}

The Upper Austrian emission inventory system was designed using the ORACLE case tool DESIGNER 2000. This tool supports the development of E/R-Diagrams and the generation of databases thereof for different platforms as well as reports (for documentation purposes).

In a first step, the system was implemented as client/server application using Microsoft Access for the clients as well as for the backend database on the server at the environmental authority. In a next phase, the back-end database will be transferred to a DB2 host. The clients will get connected via ODBC.

\subsection{Data Input}

Data input is performed with an ACCESS application currently available on three PC-clients. This includes specifically work to be done on entering the data from the questionnaires (approx. 3500 replies of 4 pages each) as well as from obligatory reports of yearly emissions from industrial sources.

A separate questionnaire was sent to municipalities to update the existing Austrian census data, which are 8 years old. This step allowed to integrate changes and new trends in heating of buildings. The data input from questionnaires was generally done manually, allowing for an additional quality check before entry into the database.

\subsection{Model computation}

The complete model computation is performed with MS-ACCESS. A set of different views (qryDefs within ACCESS) were specified and are now used in Visual Basic Routines to run the models.

We have split up the computation again into the three main categories point, line and area models. Each SNAP category is represented in at least one model. For each SNAP a separate box was created where the model computation can be chosen to be executed step by step or all at once. 


\subsection{Data Evaluation and Visualization}

The emission information can be retrieved in basically two ways. Within ACCESS, the report-function is used to generate different types of emission reports. Several standard reports and diagrams have been prepared which are intended to help fulfill the most frequent requirements an authority might

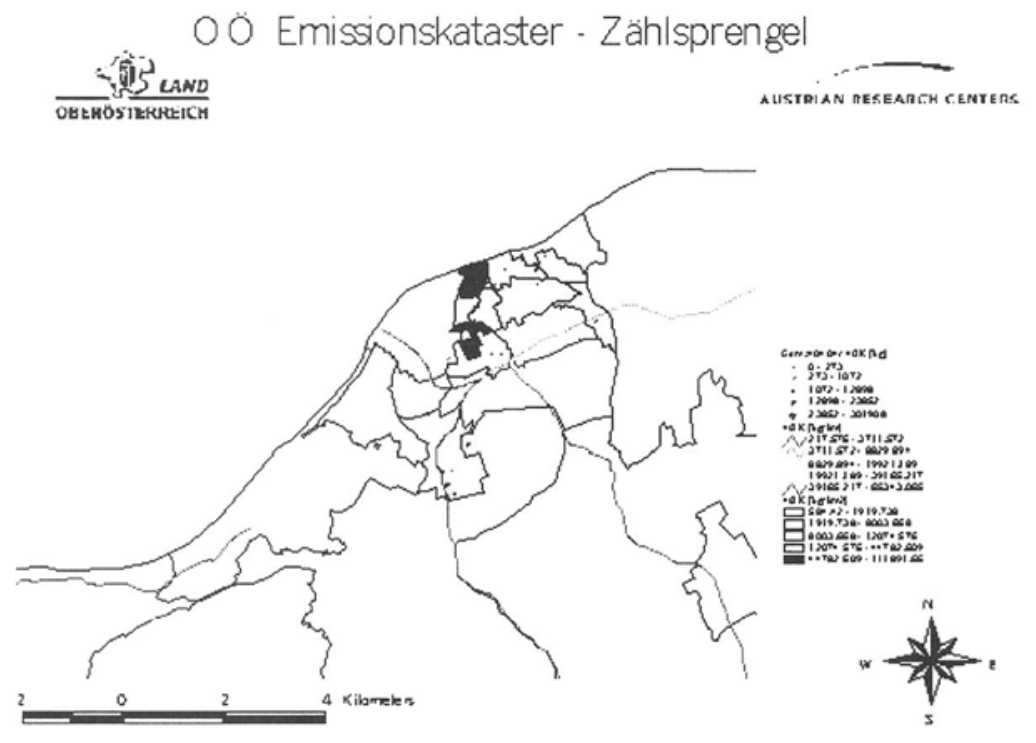

Figure 3: Emissions from point sources, area sources and line sources in an Upper Austrian town

have. Additional queries and reports may be generated by the user according to these examples given. In addition, output in the form of geographic maps has been implemented. Upon user input of pollutant, municipality/district and source class, specific maps are created, showing point, line or area emissions (Figure 3). Again, ten typical examples of evaluations needed by the authorities have been created.

Map outputs use Avenue scripts in ESRI's ArcView. Data requests are formulated as SQL-statements and transmitted to the ACCESS database via ODBC. More complex requests are prepared as Queries (QueryDefs) within ACCESS, in that case not the tables but the queries are addressed via SQL. Point location information can be readily updated from the database, as soon as the coordinates are available. 


\section{CONCLUSION}

Beside the integration of all involved persons of about ten departments of different authorities two things are to mention which were very difficult. First the development of an questionnaire which covers all information needed (and currently not included in many other existing questionnaires) and second to find a common data- as well as a computation model where you can implement a general view for evaluation and reporting processes.

The solution and implementation took us nearly two years for which we would like to thank all involved partners in the different authorities. Specially to the people in the U-LE.

\section{REFERENCES}

Bøhler T., A. Riise, S. Larsen. The AirQUIS Air Quality Assessment System: Its Use in Assessing the Effects of Pollution Abatement on Urban Air Quality and Population Exposure. In: P.M. Borrell and P. Borrell (Eds.), Proceedings of the EUROTRAC Symposium '98. WITpress, Southampton (UK), 1999, in press.

Henry R., C. Spiegelman, E.S. Park, J. Collins. Proceedings of the National Academy of Sciences 94, 6596, 1997.

IPCC, Guidelines for National Greenhouse Gas Inventories. Vol. 1: Reporting Instructions. IPCC, Bracknell (UK), 1995.

Jol, A., CORINAIR 94 Summary Report, European Environment Agency, Copenhagen (Denmark), 1997.

Keller, M., S. Hausberger, Handbuch der Emissionsfaktoren des Straßenverkehrs in Österreich. Grundlagenbericht zur Version 1.1A. Umweltbundesamt / Bundesministerium für Umwelt, Jugend und Familie, Vienna (Austria), 1998.

McInnes, G., Ed., Joint EMEP/CORINAIR Atmospheric emission inventory guidebook, 1st edition. European Environment Agency, Copenhagen (Denmark), 1996.

Orthofer R., W. Winiwarter. Spatial and Temporal Disaggregation of Emission Inventories.

In: H.Power and J.M. Baldasano (eds.): Air Pollution Emissions Inventory [J.W.S.

Longhurst, H. Power, Series Eds., Advances in Air Pollution, Vol.3] pp. 51-70, Computational Mechanics Publications, Southampton, UK, 1998.

Stanzel W., G. Jungmeier, J. Spitzer, Emissionsfaktoren und energietechnische Parameter für die Erstellung von Energie- und Emissionsbilanzen im Bereich Raumwärmeversorgung. Joanneum Research, IEF-B-02/95, Graz (Austria), 1995.

Sturm P. J., P. Blank, T. Bøhler, M. Lopes, C. Mensink, M.Volta, W. Winiwarter. Harmonised method for the compilation of urban emission inventories for urban air modelling. In: P.M. Borrell and P. Borrell (Eds.), Proceedings of the EUROTRAC Symposium '98. WITpress, Southampton (UK), 1999, in press.

U.S. EPA, Compilation of air pollutant emission factors, Volume I (AP-42), Air CHIEF CDROM edition version 5.0, U.S. Government Printing Office, Pittsburgh, PA, 1997. 